University of Nebraska - Lincoln

DigitalCommons@University of Nebraska - Lincoln

Effect of Interpersonal and Cognitive Stressors on Habituation and the Utility of Heart Rate Variability to Measure Habituation

Denise M. Feda

James N. Roemmich

Follow this and additional works at: https://digitalcommons.unl.edu/usdaarsfacpub

Part of the Agriculture Commons

This Article is brought to you for free and open access by the U.S. Department of Agriculture: Agricultural Research Service, Lincoln, Nebraska at DigitalCommons@University of Nebraska - Lincoln. It has been accepted for inclusion in Publications from USDA-ARS / UNL Faculty by an authorized administrator of DigitalCommons@University of Nebraska - Lincoln. 
RESEARCH ARTICLE

\title{
Effect of Interpersonal and Cognitive Stressors on Habituation and the Utility of Heart Rate Variability to Measure Habituation
}

\author{
Denise M. Feda ${ }^{1, *^{\dagger}}$ \& James N. Roemmich ${ }^{2}$ \\ ${ }^{1}$ Department of Pediatrics, School of Medicine and Biomedical Sciences, University at Buffalo, Buffalo, NY, USA \\ ${ }^{2}$ USDA-ARS-NPA Grand Forks Human Nutrition Research Center, Grand Forks, ND, USA
}

\begin{abstract}
Habituation is a decrease in responding to a repeated stimulus. Operant responding and salivation measure habituation in eating behaviour research. Stress may increase eating by acting as a distractor, yielding spontaneous recovery and prolonging responding for food. Our research tested differences in the ability of cognitive and interpersonal stressors to recover responding for food. We also tested heart rate variability (HRV) as a measure of habituation. Twenty women worked for portions of macaroni and cheese for 15 trials on three separate laboratory visits. Between the 12th and 13th trial, one of three different stressor types (speech, stroop and subtraction) was presented during each visit. HRV was measured continuously throughout the laboratory visits. Responding for food declined across the 12 trials with no difference in rate of habituation by visit $(p>0.8)$ There was no difference between stressor type in the magnitude of spontaneous recovery after each stressor $(p>0.8)$. Rates of habituation of HRV variables correlated $(p<0.02)$ with the rate of operant responding habituation. Cognitive and interpersonal stressors do not differ in their ability to recover reduced responding for food. HRV variables may measure habituation to food similar to operant responding. Copyright (c) 2014 John Wiley \& Sons, Ltd.
\end{abstract}

Received 14 January 2014; Revised 5 September 2014; Accepted 9 October 2014

Keywords

habituation; body weight; life stress; heart rate variability; operant responding

*Correspondence

Denise Feda, State University of New York at Buffalo, Department of Pediatrics, Farber Hall, Room G56, 3435 Main Street, Building \#26, Buffalo, NY 14214-3000, USA.

†Email: dmfeda@buffalo.edu

Published online 13 November 2014 in Wiley Online Library (wileyonlinelibrary.com) DOI: 10.1002/smi.2618

\section{Introduction}

The prevalence of obesity is a concern for public health. During 2009-2010, over 35\% of adults in the US were obese (Ogden, Carroll, Kit, \& Flegal, 2012). Behaviours that contribute to the prevalence of obesity include the use of obesogenic stress coping behaviours such as eating (Habhab, Sheldon, \& Loeb, 2009; Roemmich, Lambiase, Lobarinas, \& Balantekin, 2011).

The cumulative effect of small stressors over time can be more damaging to health than a single stressful major life event (Kanner, Coyne, Schaefer, \& Lazarus, 1981). Adults are confronted with different types of daily hassles, such as cognitive and interpersonal stressors, at least once per day (Stawski, Almeida, Lachman, Tun, \& Rosnick, 2010). There are positive associations between the number of daily hassles and snack food consumption, (Conner, Fitter, \& Fletcher, 1999) and between stress and body mass index (BMI) (Harding et al., 2014).
One way that stress may promote greater eating is by interfering with the usual slowing, or habituation, of eating. Habituation is a decrement in responding to repetitions of the same stimulus, and then recovery of responding after presentation of a distractor or a dishabituating stimulus (a stimulus that disrupts habituation and recovers responding to the initial stimulus) (Rankin et al., 2009). Specifically in eating behaviour research, habituation is a reduction in operant or physiological responding for food across repeated presentations of a food, followed by an increase in responding to the initial food after exposure to a distractor or dishabituating stimulus, such as tasting of another food or other environmental stimulus. The rate of habituation of physiological responses is associated with ingestive behaviours, food hedonics, food reinforcement and motivation to eat (Epstein, Temple, Roemmich, \& Bouton, 2009; McSweeney, Hinson, \& Cannon, 1996). McSweeney et al. (1996) were the first 
to demonstrate this paradigm in animal studies, laying the framework for other research to experiment within the construct.

Recovery in responding after habituation leads to greater food intake by increasing responding to a previously habituated food (Epstein, Temple et al., 2009; Temple, Giacomelli, Roemmich, \& Epstein, 2007). Stimuli such as a new flavour or texture of food (Epstein, Robinson, et al., 2009), television or video games (Epstein, Mitchell, \& Caggiula, 1993; Temple, Giacomelli, Kent, Roemmich, \& Epstein, 2007) can promote recovery in responding. Stressors or ruminating upon stressful events may also lead to recovery of eating by shifting allocation of attention (Epstein, Temple et al., 2009). How spontaneous recovery differs between types of stressors is unknown. This paper addresses whether interpersonal and cognitive stressors have differential effects on spontaneous recovery in eating behaviour.

Traditionally, in eating behaviour research, habituation is measured using operant responding or salivation (Epstein, Paluch, \& Coleman, 1996; Epstein et al., 2003; Temple et al., 2006). Salivation requires participants to hold dental cotton rolls in their mouths, resulting in an uncomfortable and perhaps mildly stressful experience for the research participant. Finding a more comfortable physiological measure of habituation in eating behaviour research is desirable.

Measuring heart rate variability (HRV), or the variation in the interval between consecutive heartbeats (Camm et al., 1996), is easily completed using a heart rate monitor. HRV has been used in behavioural economics experiments (Dulleck, Ristl, Markus, \& Torgler, 2011), experiments of mental stress and workload (Hjortskov et al., 2004; Hoshikawa \& Yamamoto, 1997; Jorna, 1992; Keller, Bless, Blomann, \& Kleinbohl, 2011), and emotional flexibility (Fujimura \& Okanoya, 2012). HRV has also been used as an objective measure of reported stress (Rieber et al., 2009). Previous experiments on generalized anxiety disorder used HRV to establish habituation curves amongst control and experimental groups (Thayer, Friedman, Borkovec, Johnsen, \& Molina, 2000). HRV appears to be stable over time (Stein \& Kleiger, 1999), lending the possibility of using HRV in repeated measures studies. Together, these studies suggest that HRV may be a potential alternative to using salivation protocols in research on eating behaviours. This paper addresses using HRV in eating behaviour research by testing the relationships of habituation and spontaneous recovery of HRV variables with habituation and spontaneous recovery of operant responding. Thus, this paper contributes to the literature by testing two specific aims: (1) to determine the magnitude of spontaneous recovery of operant responding for repeated presentations of food after three different stressful stimuli; and (2) to determine the utility of HRV as a measure of habituation by correlating HRV habituation with operant responding habituation.

\section{Participants and methods}

\section{Participants}

Twenty normal to obese (BMI: $\bar{M}=25, \mathrm{SD}=4.7 ; 15 \%$ minority) women, ages 18-30 years, were recruited using posted flyers and were screened for eligibility. Participants were ineligible if they did not like the study food or had metabolic disorders, eating disorders, food allergies, digestive disorders, pregnancy, colour blindness, hearing limitations or had any conditions/ psychopathology or use of medication that affected their stress reactivity or perception of stress. Only women were studied to limit potential variability due to sex.

The study was approved by the Social and Behavioral Sciences Institutional Review Board on 11/4/2011, Federal Wide Assurance ID Number FWA00008824. All participants signed written consent forms.

\section{Procedures}

Participants completed three laboratory visits. All testing was completed from 11:00 AM to 1:30 PM. Participants scheduled one appointment per week ( $\bar{M}=10$ days; median $=7$ days between appointments). Participants abstained from food for $3 \mathrm{~h}$ prior to their visit and avoided vigorous exercise, nicotine and caffeine on the day of their visit. Participants did not consume macaroni and cheese the day before or day of their visit.

During the laboratory sessions, participants were fit with a heart rate monitor and given instructions and a practice session for the operant responding task. To establish a baseline, participants rested quietly whilst reading non-stressful magazines in a seated position for $5 \mathrm{~min}$. After the rest, participants started the operant responding task to measure the rate of habituation (full description of the task in the succeeding text), working for portions of macaroni and cheese (Kraft, standard preparation). The operant responding task consisted of twelve 2-min trials, followed by a 4-min stress task, followed by an additional three 2-min trials of operant responding to demonstrate the magnitude of spontaneous recovery, measured as the increase of operant responding after exposure to the stress task. The tasks included interpersonal speech, serial subtraction and stroop task (described in the succeeding text). The order of the tasks was counterbalanced between participants. Measurements of perceived stress were taken during each lab session. At the end of the first visit, participants' height and weight were measured. At the end of the third visit, participants completed demographic (Hollingshead, 1975) and dietary restraint (Stunkard \& Messick, 1985) surveys.

\section{Rate of habituation and magnitude of spontaneous recovery}

Habituation was measured with both a behavioural task (operant responding) and physiological response (HRV variables). Operant responding for food was 
measured as the number of responses to the stimulus (or mouse clicks) the participant completed within each trial. Participants' responding was maintained by the presentation of food reinforcers, and habituation was measured as the rate of decline in operant responding across trials.

Participants were instructed to earn points towards food by clicking the computer mouse, the operant response, until a green square appeared, earning them one point (the conditional reinforcer) and one bowl of macaroni and cheese (the primary reinforcer). Points were available to the participant using a variable interval 120 s schedule (VI 120). The VI 120 schedule provided the opportunity for the participant to earn a point, on average, once every $120 \mathrm{~s}$, with a $35 \%$ time variation $( \pm 42 \mathrm{~s})$. For every point, the participant earned a $125 \mathrm{kcal}$ portion of macaroni and cheese. Macaroni and cheese is a highly palatable and easy to prepare main dish used in previous habituation studies (Epstein, Carr, Cavanaugh, Paluch, \& Bouton, 2011). Portions of food were delivered to the participants as they earned points. Participants could opt to eat the macaroni and cheese whilst continuing to earn points, consume the macaroni and cheese and continue to earn points, continue clicking without eating the macaroni and cheese or read quietly at an activity table. Eating was not permitted at the activity table. Time continued to pass for each trial regardless of the participant's chosen activity. The operant responding task has been used successfully in previous habituation research (Epstein, Robinson, et al., 2009; Epstein et al., 2011; Temple, Giacomelli, Roemmich, \& Epstein, 2008a, 2008b; Temple, Giacomelli, Roemmich, et al., 2007; Temple et al., 2009). Habituation of HRV variables was measured across trials using beat-to-beat basis recording RR intervals (time intervals between successive $\mathrm{R}$ waves). The HRV method is described in the succeeding text.

\section{Putative stressors}

\section{Speech task}

The speech task's main stressful component was an interpersonal stressor, designed to make the participant feel like they were being judged. We modified the speech portion of the Trier Social Stress Test to fit our habituation paradigm (Kirchbaum, Pirke, \& Hellhammer, 1993). Participants had 2 min to prepare, and 2 min to deliver a speech on the topic 'what makes me a good friend.' Participants were informed that their speeches would be recorded and judged based on honesty, confidence and believability. Participants were given a piece of paper with prompts to encourage developing their speech but were not allowed to use the paper during the speech.

\section{Subtraction task}

Serial mental subtraction has components of both interpersonal stress and cognitive stress (Kirchbaum et al., 1993). Subtraction requires using working memory, which may produce cognitive stress, whereas computing math in front of others may invoke fear of judgement or an interpersonal stress. To fit our habituation paradigm, we used a modified version of the task (Matthews \& Stoney, 1988). This task was divided into 2-min halves. For the first half of the task, participants completed a timed subtraction test on paper. The test included 104-digit math problems. Participants were given 2 min to complete as many as possible. Next, participants subtracted backward (out loud) from a seven-digit number by $13 \mathrm{~s}$ for min. The backwards counting was continuous, and participants were encouraged to continue if they stopped. Participants had to start over for every error they made.

\section{Stroop colours task}

The stroop task (Stroop, 1935) is a measure of cognitive flexibility and executive function (Anderson, 2001), with the main stressful component resulting from cognitive dissonance. A modified version of the traditional stroop (Stroop, 1935) task was used. This task was divided into 2-min halves. For the first $2 \mathrm{~min}$, participants viewed a series of words where the meaning of the word was incongruent with the ink colour (e.g., the word 'RED' written in green ink). A computer program read the word out loud. Participants had $3 \mathrm{~s}$ to select a button with the word that matched the ink colour (e.g., if the font colour was green, the participant clicked 'GREEN'). For the second 2 mins, participants read the word out loud and continued to select the button corresponding to the colour of ink. Each word appeared for 3 s. Any errors during the task caused a loud buzzer noise and a red ' $\mathrm{X}$ ' to appear on the computer screen.

\section{Measures}

\section{Anthropometrics}

Body weight was measured to the nearest $0.01 \mathrm{~kg}$ using a digital scale (Tanita). Height was measured to the nearest $0.01 \mathrm{~cm}$ with a SECA stadiometer. BMI was calculated as $\mathrm{kg} / \mathrm{m}^{2}$. BMI was categorized as lean $\left(\mathrm{BMI}<25 \mathrm{~kg} / \mathrm{m}^{2}\right)$ and overweight/obese $\left(\mathrm{BMI} \geq 25 \mathrm{~kg} / \mathrm{m}^{2}\right)$.

\section{Perceived stress}

Perceived stress was measured after baseline rest, before the stressor, after the stressor and after the last trial using a 10-point scale anchored with 'not at all stressed (1)' to 'very stressed (10)' (Roemmich, Feda, et al., 2011). Magnitude of change in perceived stress was computed as perceived stress after to the stressor minus perceived stress before the stressor.

\section{Measures of dietary restraint, hunger and disinhibition}

The Three Factor Eating Questionnaire (Stunkard \& Messick, 1985) was used to measure dietary restraint, 
hunger and disinhibition and has been validated (Bond, McDowell, \& Wilkinson, 2001; Stunkard \& Messick, 1985).

\section{Heart rate and heart rate variability}

Heart rate and HRV were measured using a Polar RS800CX watch on a beat-to-beat basis recording RR intervals every $1 \mathrm{~ms}$. Participants wore a transmitter across their chest and the watch on their wrist. The watch was covered with an opaque sticker to conceal the heart rate data from the participant. Artefacts in the HRV data were corrected using 'Kubios HRV Analysis' (Niskanen, Tarvainen, Ranta-aho, \& Karjalainen, 2002). Measures of time-domain were computed for the last 2 min of baseline rest and for all fifteen 2-min trials. Time-domain variables measuring heart rate and intervals between successive QRS intervals included mean HR and root mean square of successive differences (RMSSD) - the square root of the mean squared differences of successive RR intervals (Allen, Chambers, \& Towers, 2007; Camm et al., 1996). RMSSD is recommended to measure short-term components of HRV (Camm et al., 1996).

\section{Statistical analysis}

One-way repeated measures analysis of variance was used to check the stress manipulation, testing for differences in perceived stress across visits (stressor type). Individual rates (or slopes) of habituation across trials 1-12 were calculated using mixed linear regression models and the magnitude of spontaneous recovery was calculated as trial 13 response minus trial 12 response. Separate two-way repeated measures analysis of variance models were used to test differences in rate of habituation and magnitude of spontaneous recovery of operant responding and HRV variables, with BMI as a between factor and visit (type of stressor) as a repeated measures factor. Order of stressor presentation across visits was included as a covariate in all models. Correlations of HRV habituation rates and operant responding habituation were completed to test for convergent validity. Correlations were also used to test the association of rate of habituation and magnitude of spontaneous recovery with BMI, hunger, disinhibition and dietary restraint.

\section{Results}

There was an increase in perceived stress after each stressor $\left(F_{(1,16)}=37.9, p<0.001\right)$, with no difference between stressors in the magnitude of change in perceived stress $(p>0.15)$, which suggests the stress task manipulation produced an expected stress response.

As shown in Figure 1, the rate of operant responding slowed, or habituated, across trials 1-12. There was no difference in the rate of habituation of operant responding across visits $(p>0.8)$. There was an increase in responding (spontaneous recovery) after the stressor tasks (Figure 1), but no difference $(p>0.8)$ in the magnitude of spontaneous recovery across visits. There was no significant main effect of BMI status (lean vs. overweight/obese) on rate of habituation $(p>0.9)$ or the magnitude of spontaneous recovery $(p>0.3)$. Likewise, lean and overweight/obese women did not differ in their magnitude of responding after exposure to the different types of stressors $(p>0.6)$.

Nineteen participants had complete heart rate and HRV data. One participant was not included in the HRV analysis because the heart rate transponder shifted during the laboratory appointment and data were not recorded by the receiver. Time-domain HRV variables of mean HR and RMSSD by trial are shown in Figure 2. Mean HR is shown in the top panel of Figure 2 and approximates a usual habituation curve, with HR slowing as trial number increases. There was no difference in the rate of habituation across days $(p>0.4)$. There was no significant main effect of BMI status $(p>0.2)$ on HR habituation. As shown in Figure 2, there was an increase in (spontaneous recovery of) $\mathrm{HR}$ after the stressors, with no differences in the magnitude of HR spontaneous recovery across the

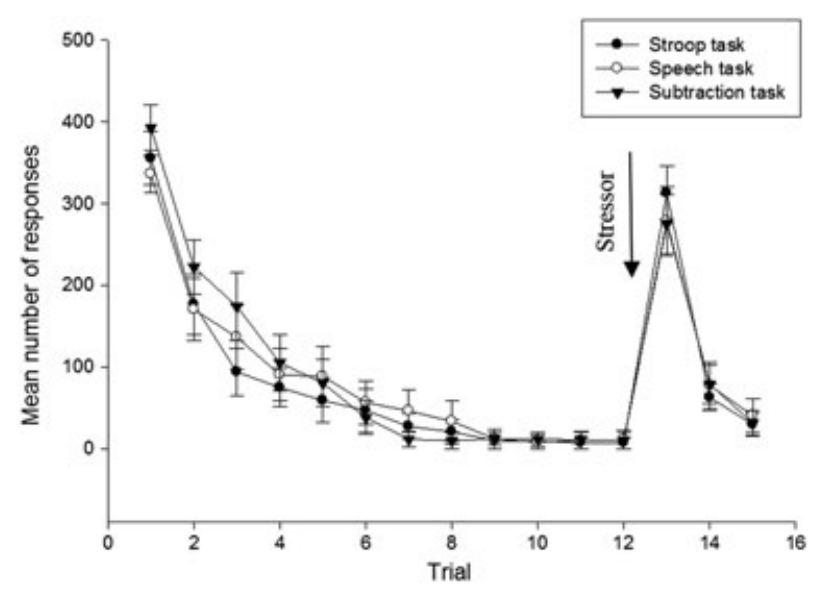

Figure 1 Mean number of operantl responses (button presses) by trial (with standard error bars) 

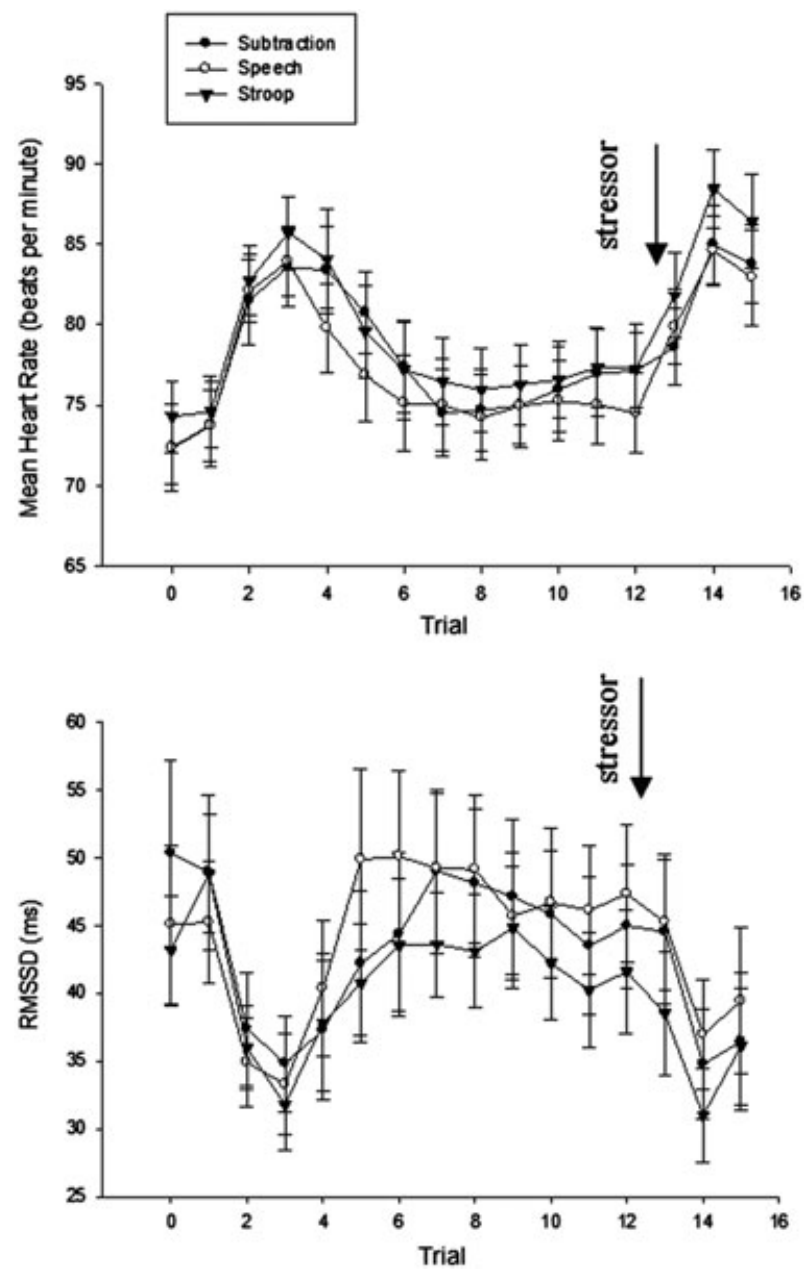

Figure 2 Habituation of heart rate variability measures across trials. Mean heart rate (top panel), and root mean square of successive differences (bottom panel)

three stressors $(p>0.6)$. There were no main effects of BMI status $(p>0.2)$ on the magnitude of HR spontaneous recovery, nor was there a significant interaction $(p>0.9)$ of BMI status and magnitude of spontaneous recovery across stressor types.

The time-domain variable RMSSD, bottom panel of Figure 2, shows an inverted habituation curve. With an inverted curve, habituation is marked by increases of RMSSD over trials, and spontaneous recovery is marked by a decrease of RMSSD. There were no differences in rate of increase of RMSSD across stressor types $(p>0.2)$. There was also no significant main effect of BMI status $(p>0.6)$. In testing the magnitude of spontaneous recovery after the stressors, there was no difference in RMSSD change between types of stressors $(p>0.8)$ There was not a significant effect of BMI status $(p>0.1)$ on RMSSD spontaneous recovery.

Because the rates of habituation and magnitude of spontaneous recovery did not differ across visits, only the rate for the subtraction visit was used to calculate correlations between habituation rate, spontaneous recovery rate and individual difference factors. The habituation rates of mean $\operatorname{HR}(\bar{M}=-0.36, \mathrm{SD}=0.72)$ and RMSSD $(\bar{M}=0.49, \mathrm{SD}=1.3)$ correlated $(r=0.53$, $p<0.02 ; r=-0.59, p<0.007$, respectively) with the operant responding habituation rate $(\bar{M}=-27.8$, $\mathrm{SD}=15.6)$. The magnitude of change between trials 12 and 13 in HRV variables (HR: $\bar{M}=1.18, \mathrm{SD}=5.9$; RMSSD: $\bar{M}=0.01, \quad \mathrm{SD}=10.9)$ did not correlate $(r=0.02, p>0.9 ; r=-0.19, p>0.4)$ with the magnitude in operant responding change $(\bar{M}=265.0$, $\mathrm{SD}=167.6$ ) between trials 12 and 13 .

Rate of operant responding habituation was not correlated with BMI $(r=-0.05, p>0.8)$; hunger $(r=-0.06, p>0.7)$; disinhibition $(r=-0.13, p>0.5)$; or dietary restraint $(r=0.34, p>0.1)$. Similarly, the rates of HR habituation and rate of RMSSD change were not correlated with BMI $(r=-0.18, p>0.4 ; r=-0.005$, $p>0.9$, all respectively); hunger $(r=-0.04, p>0.8$, $r=-0.002, p>0.9)$; disinhibition $(r=0.15, p>0.5$; $r=0.005, p>0.9)$; or dietary restraint $(r=0.19, p>0.4$; $r=-0.30, p>0.2)$. 
Magnitudes of increased operant responding (spontaneous recovery) after subtraction were not correlated with BMI $(r=-0.15, p>0.5)$; hunger $(r=0.31, p>0.1)$; disinhibition $(r=0.34, p>0.1)$; or dietary restraint $(r=0.25, p>0.2)$. Similarly, magnitudes of spontaneous recovery in HR and RMSSD, all respectively, after subtraction were not correlated with BMI $(r=-0.20, p>0.3$; $r=0.26, p>0.2)$; hunger $(r=0.22, p>0.3 ; r=-0.14$, $p>0.5)$; disinhibition $(r=-0.13, p>0.5 ; r=-0.15$, $p>0.5)$; or dietary restraint $(r=-0.31, p>0.1 ; r=0.37$, $p>0.1)$.

\section{Discussion}

This study contributes to the research on stressinduced eating by exploring the effects of different stressors on spontaneous recovery of responding for a food. There were no differences by stressor type on spontaneous recovery. Indeed, non-food stimuli such as mental arithmetic and computer and video games can act as distractors to recover responding for food (Epstein et al., 1993; Epstein, Rodefer, Wisniewski, \& Caggiula, 1992; Epstein, Temple et al., 2009).

The current work demonstrated that all three types of stressors, whether interpersonal, cognitive or a combination, recovered both behavioural operant responding for food and physiologic HRV variables. All of the stressors also recovered responding regardless of subject BMI. Thus, psychological stress is a powerful distractor and robust instigator of recovery of responding for food. Regarding rate of habituation, others have shown that adults with greater BMI habituate more slowly and that this may be one reason why people with obesity have greater energy intake (Epstein et al., 1996). We did not find that BMI affected the rate of habituation of food. Previous research on this relationship recruited lean and obese participants, whereas we included a range of BMIs. In total, only three women, or $15 \%$ of our sample, were obese. This may account for our inability to replicate previous work. Along with BMI, measures of dietary restraint, disinhibition and hunger were also not correlated with behavioural or physiologic measures of rate of habituation or magnitude of spontaneous recovery. Individual differences in dieting status or the ability to self-regulate might have explained individual differences in the rate of habituation and magnitude of spontaneous recovery. (Muraven, Tice, \& Baumeister, 1998; Vohs \& Heatherton, 2000). However, this was not tested.

This work also contributes to the literature by demonstrating a relationship between operant responding habituation to food and physiologic HRV measures of habituation, thus extending the use of HRV methodology as a measure of habituation to food. HRV is advantageous because the data can be collected without discomfort for research participants and because the data can be collected continuously. Salivation-a current physiological measure of habituation in eating behaviour research-requires inserting dental rolls in the mouth, which is uncomfortable and potentially introduces a break in experimental protocol. When comparing Figures 1 and 2, the HRV measures of HR and RMSSD (Figure 2) are similar graphically to the pattern of habituation in the operant responding task (Figure 1), although there does appear to be a short time lag with the HRV variables. This lag could be due to sensitization prior to habituation (McSweeney \& Murphy, 2009), suggesting HRV variables might be able to detect more subtle responses in habituation throughout the laboratory sessions, although this needs further study. The results suggest that HRV variables may be optional physiological measures of habituation in eating behaviour research. One qualification is that we compared HRV data with operant responding data and not salivation. The next step is to test HRV habituation against salivary habituation in order to determine if HRV can be used as a substitute for salivary habituation.

We have interpreted the findings of this study as spontaneous recovery given that an increase in responding occurred after a short period without contact with the food stimulus (Gluck, Mercado, \& Mysers, 2008). Another interpretation that was considered was that of dishabituation, 'an increase of the decremented response to the original stimulus after the presentation of a different stimulus' (Rankin et al., 2009), in this case, the stressor stimuli. The dishabituation interpretation has been applied in previous studies of responding for food (Epstein et al., 1992; Epstein et al., 1993) and could have been tested if the food stimulus remained present and subjects were allowed to eat whilst engaging in the stressors. However, because the stimulus (food) was not continuously present throughout the laboratory appointments in the current study, spontaneous recovery best describes the increase in responding after the stressor stimuli.

This study is not without limitations. The sample included only females and the results may differ in males. The sample size is small; a greater number of participants may have allowed us to confirm previous research showing slower rates of habituation of eating in overweight adults (Epstein et al., 1996). However, weight status had little effect on habituation in the current study. A power analysis indicated an effect size of 0.11 and that 1409 subjects per group would have been required to demonstrate such an effect at a power of 0.80 and alpha of 0.05 . Additionally, the HRV data during the experimental part of the sessions used 2-min intervals. This allowed for consistency with past experiments of operant responding. Previous studies of HRV have used both shorter (10 s, 25-30 s, 2 min) and longer (2 h, 24h) intervals (Algra, Tijssen, Roelandt, Pool, \& Lubsen, 1993; Dekker et al., 1997; Liao et al., 1997; Tibblin, Eriksson, Bjuro, Georgescu, \& Svardsudd, 1975; Tsuji et al., 1996) to collect HRV data. It is unclear how a longer testing duration for HRV may have impacted our findings. The stressors tested were interpersonal and/or cognitive in nature, and each was, at some 
level, a combination. Perhaps other types of stressors such as emotional stressors (e.g., mood induction) would have uncovered individual differences in spontaneous recovery efficacy of stressors. Future studies should focus on testing other stressors to further develop our understanding of stressors, spontaneous recovery, food consumption and BMI.

In conclusion, our results showed that the three types of stressors used in this study are robust instigators of recovery in responding for food in women with both low to high BMI. All three types of stressors produced similar increases in responding to a previously habituated food. Additionally, the habituation rates of HRV variables were correlated with habituation of operant responding. Future studies could have subjects recall a stressful event such as what may happen when ruminating over a recent stressor whilst eating a meal or impose different moods prior to testing. These studies could potentially improve our understanding of how stressors alter habituation to food and food consumption under more realistic conditions and to determine whether different stressors enable recovery in responding equally under exposure conditions that model common eating situations.

\section{Conflict of interest}

The authors have declared that they have no conflict of interest.

\section{REFERENCES}

Algra, A., Tijssen, J. G. P., Roelandt, J. R. T. C., Pool, J., \& Lubsen, J. (1993). Heart-rate-variability from 24-hour electrocardiography and the 2-year risk for sudden-death. Circulation, 88(1), 180-185.

Allen, J. J. B., Chambers, A. S., \& Towers, D. N. (2007). The many metrics of cardiac chronotropy: A pragmatic primer and a brief comparison of metrics. Biological Psychology, 74(2), 243-262.

Anderson, V. (2001). Assessing executive functions in children: biological, psychological, and developmental considerationst. Pediatric Rehabilitation, 4(3), 119-136.

Bond, M. J., McDowell, A. J., \& Wilkinson, J. Y. (2001). The measurement of dietary restraint, disinhibition and hunger: an examination of the factor structure of the Three Factor Eating Questionnaire (TFEQ). International journal of obesity and related metabolic disorders: journal of the International Association for the Study of Obesity, 25(6), 900-906.

Camm, A. J., Malik, M., Bigger, J. T., Breithardt, G., Cerutti, S., Cohen, R. J., ... Singer, D. H. (1996). Heart rate variability. Standards of measurement, physiological interpretation, and clinical use. European Heart Journal, 17(3), 354-381.

Conner, M., Fitter, M., Fletcher, W. (1999). Stress and snacking: A diary study of daily hassles and betweenmeal snacking. Psychology and Health, 14, 51-63.

Dekker, J. M., Schouten, E. G., Klootwijk, P., Pool, J., Swenne, C. A., \& Kromhout, D. (1997). Heart rate variability from short electrocardiographic recordings predicts mortality from all causes in middle-aged and elderly men. The Zutphen Study. American Journal of Epidemiology, 145(10), 899-908.

Dulleck, U., Ristl, A., Markus, S., Torgler, B. (2011). Heart rate variability, the autonomic nervous system, and neuroeconomic experiments. Journal of neuroscience, psychology, and economics, 4(2), 117-124.

Epstein, L. H., Carr, K. A., Cavanaugh, M. D., Paluch, R. A., \& Bouton, M. E. (2011). Long-term habituation to food in obese and nonobese women. The American Journal of Clinical Nutrition, 94(2), 371-376.

Epstein, L. H., Mitchell, S. L., \& Caggiula, A. R. (1993). The effect of subjective and physiological arousal on dishabituation of salivation. Physiology \& Behavior, 53(3), 593-597.
Epstein, L. H., Paluch, R., \& Coleman, K. J. (1996). Differences in salivation to repeated food cues in obese and nonobese women. Psychosomatic Medicine, 58(2), 160-164.

Epstein, L. H., Robinson, J. L., Temple, J. L., Roemmich, J. N., Marusewski, A. L., \& Nadbrzuch, R. L. (2009). Variety influences habituation of motivated behavior for food and energy intake in children. The American Journal of Clinical Nutrition, 89(3), 746-754.

Epstein, L. H., Rodefer, J. S., Wisniewski, L., \& Caggiula, A. R. (1992). Habituation and dishabituation of human salivary response. Physiology \& Behavior, 51(5), 945-950. Epstein, L. H., Saad, F. G., Handley, E. A., Roemmich, J. N., Hawk, L. W., \& McSweeney, F. K. (2003). Habituation of salivation and motivated responding for food in children. Appetite, 41(3), 283-289.

Epstein, L. H., Temple, J. L., Roemmich, J. N., \& Bouton, M. E. (2009). Habituation as a determinant of human food intake. Psychological Review, 116(2), 384-407.

Fujimura, T., Okanoya, K. (2012). Heart rate variability predicts emotional flexibility in response to positive stimuli. Psychology, 3(8), 578-582.

Gluck, M. A., Mercado, E., \& Mysers, C. E. (2008). Learning and memory: From brain to behavior. New York, NY: Worth Publishers.

Habhab, S., Sheldon, J. P., \& Loeb, R. C. (2009). The relationship between stress, dietary restraint, and food preferences in women. Appetite, 52(2), 437-444.

Harding, J. L., Backholer, K., Williams, E. D., Peeters, A., Cameron, A. J., Hare, M. J., ... Magliano, D. J. (2014). Psychosocial stress is positively associated with body mass index gain over 5 years: evidence from the longitudinal AusDiab study. Obesity (Silver Spring, Md), 22(1), 277-286.

Hjortskov, N., Rissen, D., Blangsted, A. K., Fallentin, N., Lundberg, U., \& Sogaard, K. (2004). The effect of mental stress on heart rate variability and blood pressure during computer work. European Journal of Applied Physiology, 92(1-2), 84-89.

Hollingshead, A. (1975). Four factor index of social status. New Haven, CT: Yale University.

Hoshikawa, Y., \& Yamamoto, Y. (1997). Effects of Stroop color-word conflict test on the autonomic nervous system responses. American Journal of Physiology-Heart and Circulatory Physiology, 272(3), H1113-H1121.
Jorna, P. G. A. M. (1992). Spectral-analysis of heartrate and psychological state - a review of its validity as a workload index. Biological Psychology, 34 (2-3), 237-257.

Kanner, A. D., Coyne, J. C., Schaefer, C., \& Lazarus, R. S. (1981). Comparison of two modes of stress measurement: daily hassles and uplifts versus major life events. Journal of Behavioral Medicine, 4(1), 1-39.

Keller, J., Bless, H., Blomann, F., \& Kleinbohl, D. (2011). Physiological aspects of flow experiences: Skills-demand-compatibility effects on heart rate variability and salivary cortisol. Journal of Experimental Social Psychology, 47(4), 849-852.

Kirchbaum, C., Pirke, K. M., Hellhammer, D. H. (1993). The 'Trier Social Stress Test' - a tool for investigating psychobiological stress responses in a laboratory setting. Neuropsychobiology, 28, 76-81.

Liao, D., Cai, J., Rosamond, W. D., Barnes, R. W., Hutchinson, R. G., Whitsel, E. A., ... Heiss, G. (1997). Cardiac autonomic function and incident coronary heart disease: A population-based case-cohort study. The ARIC study. Atherosclerosis risk in communities study. American Journal of Epidemiology, 145(8), 696-706.

Matthews, K. A., \& Stoney, C. M. (1988). Influences of sex and age on cardiovascular responses during stress. Psychosomatic Medicine, 50(1), 46-56.

McSweeney, F. K., Hinson, J. M., \& Cannon, C. B. (1996). Sensitization-habituation may occur during operant conditioning. Psychological Bulletin, 120(2), 256-271.

McSweeney, F. K., \& Murphy, E. S. (2009). Sensitization and habituation regulate reinforcer effectiveness. $\mathrm{Neu}$ robiology of Learning and Memory, 92(2), 189-198.

Muraven, M., Tice, D. M., \& Baumeister, R. F. (1998). Self-control as limited resource: Regulatory depletion patterns. Journal of Personality and Social Psychology, 74(3), 774-789.

Niskanen, J. P., Tarvainen, M. P., Ranta-aho, P. O., Karjalainen, P. A. (2002). Software for advanced HRV analysis: Department of Applied Physics Report Series.

Ogden, C. L., Carroll, M. D., Kit, B. K., \& Flegal, K. M. (2012). Prevalence of obesity in the United States, 20092010, NCHS data brief (Vol. 82). Hyattsville, MD: National Center for Health Statistics.

Rankin, C. H., Abrams, T., Barry, R. J., Bhatnagar, S., Clayton, D. F., Colombo, J., ... Thompson, R. F. 
(2009). Habituation revisited: an updated and revised description of the behavioral characteristics of habituation. Neurobiology of Learning and Memory, 92(2), 135-138.

Rieber, N., Betz, L., Enck, P., Muth, E., Nikendei, C., Schrauth, M., ... Zipfel, S. (2009). Effects of medical training scenarios on heart rate variability and motivation in students and simulated patients. Medical Education, 43(6), 553-556.

Roemmich, J. N., Feda, D. M., Seelbinder, A. M., Lambiase, M. J., Kala, G. K., \& Dorn, J. (2011). Stressinduced cardiovascular reactivity and atherogenesis in adolescents. Atherosclerosis, 215(2), 465-470.

Roemmich, J. N., Lambiase, M. J., Lobarinas, C. L., \& Balantekin, K. N. (2011). Interactive effects of dietary restraint and adiposity on stress-induced eating and the food choice of children. Eating Behaviors, 12(4), 309-312.

Stawski, R. S., Almeida, D. M., Lachman, M. E., Tun, P. A., \& Rosnick, C. B. (2010). Fluid cognitive ability is associated with greater exposure and smaller reactions to daily stressors. Psychology and Aging, 25(2), 330-342.

Stein, P. K., \& Kleiger, R. E. (1999). Insights from the study of heart rate variability. Annual Review of Medicine, 50, 249-261.
Stroop, J. (1935). Studies in interference in serial verbal reactions. Journal of Experimental Psychology, 18, 643-662. Stunkard, A. J., \& Messick, S. (1985). The three-factor eating questionnaire to measure dietary restraint, disinhibition and hunger. Journal of Psychosomatic Research, 29(1), 71-83.

Temple, J. L., Bulkley, A. M., Badawy, R. L., Krause, N., McCann, S., \& Epstein, L. H. (2009). Differential effects of daily snack food intake on the reinforcing value of food in obese and nonobese women. American Journal of Clinical Nutrition, 90(2), 304-313.

Temple, J. L., Giacomelli, A. M., Kent, K. M., Roemmich, J. N., \& Epstein, L. H. (2007). Television watching increases motivated responding for food and energy intake in children. American Journal of Clinical Nutrition, 85(2), 355-361.

Temple, J. L., Giacomelli, A. M., Roemmich, J. N., \& Epstein, L. H. (2007). Overweight children habituate slower than non-overweight children to food. Physiology \& Behavior, 91(2-3), 250-254.

Temple, J. L., Giacomelli, A. M., Roemmich, J. N., \& Epstein, L. H. (2008a). Dietary variety impairs habituation in children. Health psychology: official journal of the Division of Health Psychology, American Psychological Association, 27(1 Suppl), S10-19.
Temple, J. L., Giacomelli, A. M., Roemmich, J. N., \& Epstein, L. H. (2008b). Habituation and withinsession changes in motivated responding for food in children. Appetite, 50(2-3), 390-396.

Temple, J. L., Kent, K. M., Giacomelli, A. M., Paluch, R. A., Roemmich, J. N., \& Epstein, L. H. (2006). Habituation and recovery of salivation and motivated responding for food in children. Appetite, 46(3), 280-284.

Thayer, J. F., Friedman, B. H., Borkovec, T. D., Johnsen, B. H., \& Molina, S. (2000). Phasic heart period reactions to cued threat and nonthreat stimuli in generalized anxiety disorder. Psychophysiology, 37(3), 361-368.

Tibblin, G., Eriksson, C.-G., Bjuro, T., Georgescu, D., Svardsudd, C. (1975). Heart rate and heart rate variability a risk factor for the development of ischaemic heart disease (IHD) in the "Men born in 1913 study" a ten years follow-up. IRCS Med Sci Cardiovasc Sys Soc Occup Med, 3, 95.

Tsuji, H., Larson, M. G., Venditti, F. J., Jr., Manders, E. S., Evans, J. C., Feldman, C. L., \& Levy, D. (1996). Impact of reduced heart rate variability on risk for cardiac events. The Framingham Heart Study. Circulation, 94(11), 2850-2855.

Vohs, K. D., \& Heatherton, T. F. (2000). Self-regulatory failure: A resource-depletion approach. Psychological Science, 11(3), 249-254. 